\title{
The Effect of Gallic Acid Supplement and Resistance Exercise on the Bio-markers of Liver in Intoxicated Male Rats of Anabolic Steroid
}

Kazem Ranjbar (PhD)

Physical Education (Exercise

Physiology Orientation) Islamic Azad University, Tehran Branch, Tehran, Iran

Hassan Matin Homaie ((PhD)

Faculty of Physical Education and Sport Sciences, Islamic Azad

University, Tehran Branch, Tehran,

Iran

Mohammad Ali Azarbayejani (PhD) Faculty of Physical Education, Islamic Azad University, Tehran Branch,

Tehran, Iran

Maghsoud Piri (PhD)

Faculty of Physical Education, Islamic

Azad University, Tehran Branch,

Tehran, Iran

Corresponding author: Hassan Matin Homaie

Email:hasanmatinhomaee@yahoo.com Tel: +989123680810

Address: Department of Physical Education and Sport Sciences, Islamic Azad University, Tehran Branch, Tehran, Iran

Received: 25 Feb 2019

Revised: 03 Jul 2019

Accepted: 03 Jul 2019

(c) (i) (5)

This work is licensed under a Creative Commons Attribution 4.0 License.
Abstract

Background and Objectives: Liver is one of the vital organs of the human body. Antioxidants have been shown to play important roles in reducing liver injuries. The aim of this study was to examine the effects of gallic acid supplementation and resistance exercise on liver damage biomarkers in male rats intoxicated by steroid anabolic.

Materials and Methods: Forty-two male Wistar rats were randomly divided into six equal groups: control, sham, steroid anabolic $(5 \mathrm{mg} / \mathrm{kg})$, steroid anabolic $(5 \mathrm{mg} / \mathrm{kg})+$ gallic acid supplementation $(50 \mathrm{mg} / \mathrm{kg})$, steroid anabolic $(5 \mathrm{mg} / \mathrm{kg})+$ resistance exercise, and steroid anabolic $(5 \mathrm{mg} / \mathrm{kg})+$ gallic acid supplementation $(50 \mathrm{mg} / \mathrm{kg})+$ resistance exercise. Except for control and sham groups, all groups received (injection) steroid anabolic at a dose of $5 \mathrm{mg} / \mathrm{kg}$ body weight once a week. The resistance exercise protocol was comprised of three weekly exercise sessions by 5 rep/3 set of climbing ladder for eight weeks. Data were analyzed via ANOVA and Tukey's post hoc test at a significance level of $\mathrm{P}<0.05$.

Results: The hepatic enzymes (alanine aminotransferase, aspartate aminotransferase and alkaline phosphatase) and bilirubin (total and direct), "In the gallic acid supplementation group $(\mathrm{P}<0.01, \mathrm{p}<0.01, \mathrm{p}<0.01, \mathrm{p}<0.02$, and $\mathrm{p}<0.05$, respectively), resistance training group $(\mathrm{p}<0.02, \mathrm{p}<0.01, \mathrm{p}<0.01, \mathrm{p}<0.01$, and $\mathrm{p}<0.05$, respectively), and the gallic acid supplementation group with resistance exercise $(\mathrm{P}<0.02, \mathrm{p}<0.01$, $p<0.01, p<0.01$, and $p<0.01$, respectively)" were significantly reduced compared to the anabolic steroid group.

Conclusions: Gallic acid supplementation and resistance exercise significantly reduce liver damage biomarkers. However, the simultaneous use of resistance exercise and gallic acid supplementation has no increasing effects on these biomarkers.

Keywords: Anabolic Agents, gallic acid, Resistance Training.

This paper should be cited as: Ranjbar K, Matin Homaie H, Azarbayejani M, Piri M [The Effect of Gallic Acid Supplement and Resistance Exercise on the Bio-markers of Liver in Intoxicated Male Rats of Anabolic Steroid]. mljgoums. 2020; 14(1): 44-49 


\section{INTRODUCTION}

An increase has been recently observed in the tendency to use drug plants for the treatment of different diseases. Certain natural and non-natural compounds have antioxidant properties that play critical roles against the destructive factors of liver (1-4). Gallic acid ( $3,4,5$ Trihydroxy benzoic acid) is a trihydroxybenzoic acid found in plants such as barberry pomegranate, nut fruits (5) berries and tea leaves (6). Gallic acid is considered as a highly natural antioxidant which reduces free radical activity (7). Moreover, gallic acid and its derivatives affect cancer cell duplication $(8,9)$, and different studies have shown the liver protection ability of this acid. For instance, Tung et al. reported that the herbal extract of gallic acid was able to reduce the liver poison derived from CCL4. They further observed that the reduction in the poison due to the prevention of lipid peroxidation, increased the activity of antioxidant enzyme and reduced ALT activity and AST (10).

Liver is the most metabolic organ and detoxification responsible of different material that have an important role in many processes of such as glucose homeostasis, making necessary protein of plasma, making lipoprotein and lipid, making and secretion of bile acids and storage of vitamins (1). Several endogenous and exogenous factors such as poisons (11), drugs (11), hormones (12) and some pathologic ingredients (13) can endanger the liver hepatocyte life. One of the damaging factors is anabolic steroid (14-16) which derives compounds from testosterone (15) to increase power and resistance in canine, equine and humans (athletes) through increasing the production of muscular proteins and constituent basic materials associated with sexual hormones $(15,16)$. Boldenone (17-bBol) is an anabolic steroid with high anabolic and moderate androgenic properties. Tousson et al. showed that Boldenone damaged liver (14-16). Specifically, they reported that nine weeks of Boldenone usage induced damage in the liver, kidney and testicles of rats (14). Similarly, Matinhomaee et al. showed that 12week Boldenone consumption damaged the liver of rats, an effect which was more clear at higher doses $(0.5 \mathrm{mg}$ in $\mathrm{kg}),(15)$. On the other hand, some studies have shown that resistance exercises might improve liver enzymes (17-21). Zelber et al. studied the effect of resistant exercise on non-alcoholic fatty liver. The results showed that three months of resistance exercise reduced fat and liver enzymes (17). Also, Shamsoddini et al. found that resistance exercises such aerobic exercises increased liver fat and reduced its enzymes (19). Similarly, Bashiri et al. showed that eight weeks of resistance exercise and supplementary creatine use had no significant effect on liver enzyme (2). In Damor et al. study, no changes were observed in liver enzymes following two months of high resistance exercise (22). Likewise, Petterson et al. observed that high resistance exercise was able to increase liver enzymes in hte blood (23). The aforementioned studies indicate contradictory results with regards to the effect of resistant exercise on liver enzyme. Research has shown that gallic acid is probably capable of reducing liver enzyme secretion. Therefore, the present research investigated the effect of eight weeks of resistance exercise coupled with gallic acid consumption on the liver enzymes of male rates intoxicated with anabolic steroid.

\section{MATERIALS AND METHODS}

Forty-two male Wistar rats were prepared from the animal houses of Sari Azad University and categorized into six equal groups: healthy control group, experimental group, Boldenone group, gallic acid supplement group, exercise group, and exercise and gallic acid supplement group. Except for the healthy control and experimental groups, all groups were intramuscularly administered with steroid anabolic (Boldenone brand equipoise made in Meditech Company, Germany) with a dosage of $0.5 \mathrm{mg} / \mathrm{kg}$ once a week.

Rats were weighed weekly and gallic acid with brand sigma Aldrichest (St. Louis. Mo.USA) consumed orally at a concentration of 50 $\mathrm{mg} / \mathrm{kg}$. The animals were kept in a standard cage with 12-hour light, favorable ventilation and free access to water and food. This study was carried out in line with the Animal Breeding Guide (24).

The eight-week resistance program included ladder climbing (one meter height and 85degree slope) with three weekly sessions, and resistance was created by putting the weight on animal tail. Each session consisted of three sets with five repetition that there were one- 
minute rest between each repetitions and two minutes rest between each sets. In the first week, the weight of the rats was increased by $50 \%$, with $10 \%$ weekly increase depending on the body weight of the mouse. A final $120 \%$ increase occurred in the body weight of the rats at the end of the week.

After anesthetizing, an anatomy was performed on the surgery board of rodents through fixing animal, and blood samples were taken from the animals' heart. Subsequently, the blood samples were transferred to the lab. The levels of aspartate aminotransferase, alanin aminotransferase, alkaline aminotransferase, albumin and billirubin were measured using PARS AZMUN Kit and enzymatic method with an accuracy of 0.1 unit per liter. The bilirubin was measured by Diazo method and serum albumin was measured using photometric method. In this study, descriptive and inferential statistics were used for statistical analysis. Smirnovcolomograph test was employed to determine the natural distribution of data. The means of all the obtained values were compared with one-way analysis of variance. The differences obtained from the Tukey sample were used to compare group pairs, and the significance level was considered $\mathrm{p}<0 / 05$.

\section{RESULTS}

Table 1 shows the significant increase in ALP, ALT and AST serum enzymes in the Boldenone group compared to the control group. However, no significant increase was observed in the gallic acid group with a dosage of $50 \mathrm{mg} / \mathrm{kg}$ and in the resistant training activity of the ALP, ALT, and AST enzymes. Further consumption gallic acid with resistance training (group 6) could inhibited the increase in the enzymes.

Table 1- comparison of serum ALP, ALT and AST enzymes based on U/lit in different groups

\begin{tabular}{|c|c|c|c|c|c|}
\hline Number & \multicolumn{2}{|l|}{ Groups } & AST (IU/lit) & ALT (IU/lit) & ALP (IU/lit) \\
\hline 1 & \multicolumn{2}{|l|}{ Control } & $146 \pm 17.08$ & $55.33 \pm 18.29$ & $225.33 \pm 74.71$ \\
\hline 2 & \multicolumn{2}{|l|}{ Experimental } & $143.4 \pm 22.72$ & $53.8 \pm 16.05$ & $221.4 \pm 59.05$ \\
\hline 3 & \multicolumn{2}{|c|}{ Boldenone } & $219.5 \pm 22.3 *$ & $95.16 \pm 12.2 *$ & $360.66 \pm 36.3 *$ \\
\hline 4 & \multicolumn{2}{|c|}{ Boldenone+resistance exercise } & $173.74 \pm 24.71 * *$ & $70.22 \pm 25.85 * *$ & $249.85 \pm 55.61 * *$ \\
\hline 5 & \multicolumn{2}{|c|}{ Boldenone+ gallic acid } & $169.71 \pm 30.65 * *$ & $69.14 \pm 8.90 * *$ & $265.71 \pm 56.30 * *$ \\
\hline 6 & $\begin{array}{l}\text { Boldenone+gallic } \\
\text { exercise }\end{array}$ & acid+resistance & $165.58 \pm 22.13 * *$ & $70.42 \pm 8.93 * *$ & $269.83 \pm 27.60 * *$ \\
\hline \multirow{2}{*}{\multicolumn{2}{|c|}{ Difference between groups }} & $\mathbf{F}$ & 4.168 & 3.395 & 3.256 \\
\hline & & $\mathbf{p}$ & 0.001 & 0.006 & 0.008 \\
\hline
\end{tabular}

*Each column represents a significant difference with the control group.

**Each column represents a significant difference with the gallic acid group.

Table 2 shows a significant increase in the total bilirubin and direct bilirubin activity in the Boldenone group compared to the control and experimental groups However, there was no significant increase in the gallic acid consumption group and resistance training group; moreover, in the gallic acid and resistant training group, the total bilirubin and bilirubin activity were not significantly higher than the control and experimental groups. Also, there was no significant difference between the levels of albumin groups in the table.

Table2- Comparison of bilirubin total, bilirubin and albumin activity

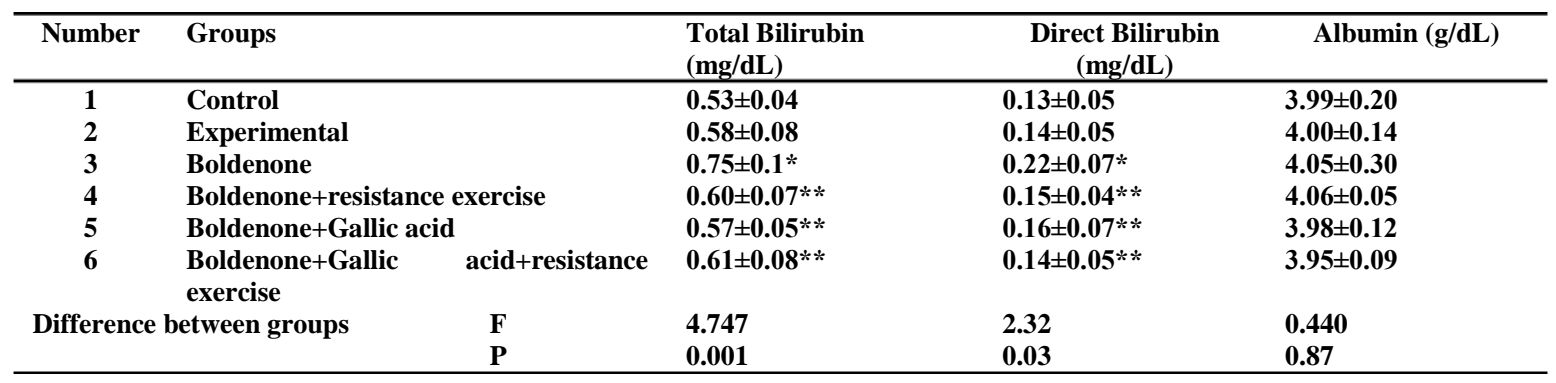

*Each column represents significant difference from the control group.

**Each column represents a significant difference from the Gallic acid. 


\section{DISCUSSION}

Boldenone is an anabolic steroid which increases muscle mass and positive nitrogen balance and reduces protein degradation, and water, nitrogen, sodium, potassium and calcium intake (15). Similar to all other anabolic-androgenic steroids, Boldenone is a banned substance (14). Research has shown that Boldenone damages liver $(14,15)$, the largest gland in the body involved in many metabolic functions such as proteinization and detoxification (25). The change in the integrity of the liver cell membrane results in the introduction of naturally occurring enzymes within the cytosol located in the blood, which is a good indicator of liver status. Increased activity of liver enzymes in serum is the main indicator of liver damage (1). The return of the liver enzyme activity to its normal state is one of the main indicators of liver therapy (25).

The results of this study showed a significant increase in the liver enzymes in the Boldenone group (Dosage $0.5 \mathrm{mg} / \mathrm{kg}$ ) compared to the control and the experimental groups, which is indicative of liver damage. Furthermore, a significant change was observed in the liver enzymes in the gallic acid consumption and Boldenone group compared to the boldenone group alone. Such decrease is indicative of the improved hepatic status following the use of gallic acid. Various studies have attributed the cause of hepatic protection to antioxidant properties $(7,8)$. Tung et al. investigated the effects of Acacia cofusa herb extract and active ingredient (gallic acid) on the liver affected by tetrachloride. They reported that gallic acid intake protected liver, modified the liver enzymes, and inhibited liver prooxidant (10). Mahbooob et al. observed that gallic acid intake protected the liver against the damage induced by paracetamol in mice (26). Gallic acid has also been shown to modify liver biomarkers (26). Bouasla et al. showed that the three-week consumption of gallic acid reduced the liver biomarkers. It is to be noted that levels of liver biomarkers increased in the groups that took sodium fluoride. However, the use of gallic acid protected the liver (27). Also, Ozman et al. showed that a weekly consumption of gallic acid resulted in liver protection in rats exposed to Ischemic reperfusion (28). The results of the abovementioned studies are consistent with the results of the present study in that gallic acid reduced the liver damage biomarkers. Furthermore, gallic acid eliminated free radicals $(26,27)$. The present study showed a significant change in the amount of liver enzymes in the resistance group with Boldenone consumption compared to Boldenone administration alone. Karampour et al. showed that three weekly sessions of resistance training for two months resulted in a significant decrease in liver enzymes (ALT, AST), which is consistent with the results of the present study (21). Waldron also investigated the changes in ALT, AST, ALP Urea, bilirubin and creatinine in the weightlifters participating in the Olympics. These athletes simultaneously underwent intense resistant training for five weeks and used creatine. The results of the present research showed that in the first weeks, ALT, ALP, and AST increased while in the final weeks of the first level, they decreased. Also, the bilirubin level was reduced the initial level. However, Alnumin did not significantly change during the training period (18). Similarly, Zellber et al. studied the effects of resistance training on non-alcoholic liver. They reported that resistance training for three months reduced the amount of fatty liver and the amount of ALT and AST, which is consistent with the results of the current study (17). Radak et al. showed in an overview article that exercise coupled with the increased need for ATP augmented aerobic and anaerobic metabolism, increasing the reactive oxygen species (29). The inhibitory effect of regular exercise is at least partly due to the compatibility with oxidative stress. The process of compatibility associated with exercise isn't just about generates ROS levels, but also increases the antioxidants and the activity of the enzymes, regenerating the oxidative-degradation. Perhaps the reduction in the liver enzymes is attributed to these compatibility, indicating hepatic tissue repair.

\section{CONCLUSION}

The enzymes of liver (AST, ALT, ALP) decreased in Group 6 (boldenone+exercise+gallic acid) compared with Group 3 (Boldenone). However, no significant difference was observed between Group 6 and Group 4 (boldenone+ exercise), Group 6 and Group 5 (boldenone+gallic acid), and Group 4 and Group 5. These results show 
that gallic acid supplementation with resistance training than gallic acid or resistance training by itself, does not has a greater impact on the modification of liver damage. It is important that this issue be accurately investigated in hepatic histology studies.

\section{REFERENCES}

1. Ebrahimi S, Sadeghi H, Pourmahmoudi A, Askariyan SH, Askari S. Protective Effect of Zizphus Vulgaris Extract, on LiverToxicity in Laboratory Rats. Armaghane danesh Journal. 2010; 16(2): 172-80. (Persian)

2. Bashiri J, Gaeini A, Nikbakht H, Hadi H, Bashiri M. Effect of Concurrent Creatine Monohydrate Ingestion and Resistance Training on Hepatic Enzymes Activity Levels in Non"Athlete Males. IJEM. 2010; 12(1): 42-7. (Persian)

3. Movahedian Ataar A, Eshraghi A, Asgari S, Naderi G, Badiee A. Antioxidant Effect of Ziziphus vulgaris, Portulaca oleracea, Berberis integerima and Gundelia tournefortti on Lipid Peroxidation, Hb Glycosylation and Red Blood Cell Hemolysis. J Med Plants. 2011; 4(40): 80-88. (Persian)

4. Chen CF, Lee JF, Wang D, Shen K1, Lin MH. Water Extract of Zizyphus Jujube Attenuates Ischemia/Reperfusion-Induced Liver Injury in Rats (PP106). Trans Pro. 2010; 42: 741-743.

5. Kavitha AV, Jagadeesan G. Role of Tribulus terrestris (Linn.) (Zygophyllacea) against mercuric chloride induced nephrotoxicity in mice, Mus musculus (Linn.). J Environ Biol. 2006; 27(2): 397-400.

6. Monach C, Scalbert A, Morand C, Remesy C, Jimenez L. Polyphenol: food sources and bioavailability. Am J Clin Nut. 2004; 79(5): 727-47.

7. Polewski K, Kniat S, Slawinska D. Gallic acid, a natural antioxidant, in aqueous and micellar environment: spectroscopic studies. Curr Top Biophys. 2002; 26: 217-27.

8. Kim YJ. Antimelanogenic and antioxidant properties of gallic acid. Biol Pharm Bull. 2007; 30: 1052-1055.

9. Jain A, Soni M, Deb L, Jain A, Rout SP, Gupta VB, et al. Antioxidant and hepatoprotective activity of ethanolic and aqueous extracts of Momordica dioica Roxb. Leaves. J Ethnopharmacol. 2008; 115(1): 61-66.

10. Yu-Tang T, Jyh-Horng W, Chi-Chang H, Hsiang-Chi $\mathrm{P}$, Ya-Ling C, Suh-Ching Y, et al. Protective effect of Acacia confusa bark extract and its active compound gallic acid against carbon tetrachloride-induced chronic liver injury in rats. Food Chem Toxicol. 2009; 47(6): 1385-92. doi: 10.1016/j.fct.2009.03.021.

11. Murray KF, Hadzik N, Wirth S, Basset M, Kelly D. Drug- related hepatotoxicity and acute liver failure. J Pediatr Gastroenterol Nutr. 2008; 47(4): 395-405. doi: 10.1097/MPG.0b013e3181709464.

12. Torres S, Diaz BP, Cabrera JJ, Diaz- Chico JC, DiazChico BN, Lopez-Guerra A. Thyoid hormone regulation of rat hepatocyte prolierration and polyploidization. Am J Physiol. 1999; 276(1): G155-63. doi: 10.1152/ajpgi.1999.276.1.G155.

\section{ACKNOWLEDGEMENT}

We wish to thank all those who assisted us in collecting, recording, and reporting the data in this study.

\section{CONFLICT OF INTEREST}

We have no conflict of interest to declare.

13. Natori S, Rust C, Stadheim LM, Srinivasan A, Burgart LJ, Gores GJ. Hepatocyte apoptosis is a pathologic feature of human alcoholic hepatitis. J Hepatol. 2001; 34(2): 248-53.

14. Tousson E, El-Gerbed MSA, Shleby S. Effect of maturity on histopathological alteration after growth promoter boldenone injection in rabbits. J Am Sci. 2011; 7: 1074-80.

15. Matinhomaee H, Ziaolhagh SJ, Azarbayjani MA, Piri M. Effects of Boldenone consumption and resistance exercise on hepatocyte morphologic damages in male Wistar rats. Eur J Exp Bio. 2014; 4:211-14.

16. Huan-Xia Z, Hai-Sheng Z, and Shu-Fang Y. Phenolic compound and its antioxidant activity in ethanolic extracts from seven cultivars of Chinese jujube. Food Sci Hum Well. 2014; 3: 183-90.

17. Zelber-Sagi S, Buch A, Yashua H, Vaisman N, Webb $\mathrm{M}$, Shibolet O. Effect of resistance training and non alcoholic fatty liver disease a randomized-clinical trial. World J Gastro. 2014; 20: 4382-92. DOI: 10.3748/wjg.v20.i15.4382.

18. Waldron JE, Pendlay GW, Kilgore TG, Haff GG, Reeves JS, and Kilgore JK. Concurrent creatine monohydrate supplementation and resistance training does not affect markers of hepatic function in trained weightlifter. J Exer Physio. 2002; 5(1): 57-64.

19. Shamsoddini A, Sobhani V, Ghamar Chehreh ME, Alavian SM, and Zaree A. Effect of aerobic and resisitance exercise training on liver enzymes and hepatic fat in Iranian men with nonalcoholic fatty liver disease. Hepat Mon. 2015; 15(10): e31434. doi: 10.5812/hepatmon.31434.

20. El-Moghazy M, Tousson E, and Sakeran MI. Changes in the hepatic and renal structure and function after a growth promoter boldenone injection in rabbits. Ani Bio. 2012; 62: 171-80.

21. Karampour S, Mahmodi Y, and Valizadeh R. The effect of ten weeks resistance training on AST and ALT of fatty liver patients. J Resea App Sci. 2014; 1: 146-149. doi: 10.5812/hepatmon.31434.

22. Damor K, Mittal K, Bhalla AS, Sood R, Pandey RM, Guleria $\mathrm{R}$, et al. Effect of progressive resistance exercise training on hepatic fat in Asian Indians with non alcoholic fatty liver disease. Bri J Med Med Res. 2014; 4: 114-24.

23. Pettersson J, Hindorf U, Persson P, Bengtsson T, Malmqvist U, Werkström V, et al. Muscular exercise can cause highly pathological liver function tests in healthy men. Br J Clin Pharmacol. 2008; 65: 253-9. 
24. Bancroft JD, and Cook HC. Manual of histological techniques and their diagnostic application. $2^{\text {nd }} \mathrm{ed}$. Edinborgh: Chruchil livingstone, 1994: 23-26.

25. Deepraj $\mathrm{P}$ and Karthika $\mathrm{P}$. Liver injury and hepatocellular carcinoma: A review. IJRPC. 2012; 2: 2231-81.

26. Rasool MK1, Sabina EP, Ramya SR, Preety P, Patel $\mathrm{S}$, Mandal $\mathrm{N}$, et al. Hepatoprotective and antioxidant effects of gallic acid in paracetamol-induced liver damage in mice. J Pharm Pharmacol. 2010; 62(5): 63843. doi: 10.1211/jpp.62.05.0012.
27. Bouasla A, Bouasla I, Boumendjel A, El Feki A, Messarah M. Hepatoprotective Role of Gallic Acid on Sodium Fluoride-Induced Liver Injury in Rats. Int $\mathrm{J}$ Pharm Sci Rev Res. 2014; 29(2): 14-18.

28. Ozmen A, Canbek M, Senturk H, Bayramoglu G, Uyanoglu M. Possible protective effects of gallic acid against hepatic ischemia-reperfusion injury in rats. Spatula DD. 2012; 2(2):101-10. DOI: 10.5455/spatula.20120416113343.

29. Radak Z, Chung HY, and Goto S. Systemic adaptation to oxidative induced by regular exercise. Free Rad Bio Med. 2008; 44(2): 153-9. doi: 10.1016/j.freeradbiomed.2007.01.029. 